\title{
1. Practice as accomplishment
}

Working practices constitute the everyday life of organizing and they may be investigated as the spatio-temporal accomplishment by knowledgeable practitioners in relation with tools, discourses, technologies, rules. A specific interest in practices as ongoing accomplishments and competent 'doing' has its roots in ethnomethodology as the research programme aimed at representing the practical methods constituting knowledge in the world. ${ }^{1}$ To give an example of 'practical accomplishment', Garfinkel (1967, p. 9) refers to a centre for suicide prevention. This centre has the following task: 'that deaths are made accountable-for-all-practical-purposes are practical organizational accomplishments. Organizationally the Suicide Prevention Center consists of practical procedures for accomplishing the rational accountability of suicidal deaths as recognizable features of the settings in which that accountability occurs'. This accomplishment consists of members doing and recognizing an accomplished familiarity in an unproblematic way.

Phenomena like language, knowledge, work, organization, ethics, responsibility or accountability may be investigated as situated accomplishments by the parties whose local practices make up such a phenomenon (Lynch, 2001). Instead of putting questions around ontology - what friendship is, what ethics is or what coordination is - a practice approach shifts such questions into: how is friendship accomplished, how is ethics 'done' in practical situations, how is coordination achieved in practice? Often in this case we use the expression 'in practice' to indicate the gap between a phenomenon 'in theory' and the concrete way to make it happen. We are going to see how situated working practices make up an accomplished instance of organizing.

What do people do when they work? How do they recognize that a particular 'doing' belongs to a specific practice? When they work is that all they do? How does work differ from non-work? The more traditional sociologists of work have preferred to consider it a 'macro' social phenomenon - as employment - leaving 'micro' analysis to other disciplines or to other sociological traditions. This is the so-called 'missing what' (Garfinkel and Wieder, 1992, p. 203), which escapes traditional studies on work. It is this perspective that has been resumed by the practice-based ${ }^{2}$ 
studies that continue the phenomenological and ethnomethodological tradition and take up Barley and Kunda's (2001) invitation to 'bring work back in' organization studies. The study of situated working practices also responds to a need for better understanding of the difference between prescribed work and real work (Licoppe, 2008) - a problem long present in the European sociology of work.

To understand this latter perspective, consider the phenomenological definition provided by Alfred Schütz (1962, p.212), which treats work from another point of view: 'Working, then, is action in the outer world, based upon a project and characterized by the intention to bring about the projected state of affairs by bodily movements'. This definition places particular emphasis on work as an activity directed towards the world, that is intended to accomplish a project, and above all one that involves the human body. Too often, in fact, it is forgotten that working practices are performed by a body, by its psycho-physical capacities, and that bodies are differently sexed. Workers are not abstract labour but sociomaterial and symbolic bodies.

From this perspective, working is a being-in-the-world tied to the accomplishment of a project through physical activities that are situated in time and space (Dall'Alba and Sandberg, 2010; Dall'Alba et al., 2018). Defining work as a situated activity means focusing the sociological analysis of work on working practices as modes of action and knowledge, emerging in situ from the dynamics of sociomaterial interactions (Gherardi, 2006). This definition is rooted theoretically in social phenomenology, ethnomethodology and symbolic interactionism. Since the 1990s (together with other studies on distributed knowledge, cultural cognitive psychology, activity theory and situated learning), it has given rise to a new strand of social studies on working and organizing which fall under the heading of 'practice-based studies' or 'studies of knowing in practice'.

Emerging today is a perspective of study founded on practice theories as an analytical and interpretative alternative to the traditional one, because study of work as a collective knowledgeable doing is necessary to gain better understanding of technological practices where interaction takes place both in co-presence and at a distance, where workers simultaneously maintain and alter practices (jobs are re-made) (Price et al., 2009), and where communication and responsibility are crucial for the support in real time of the capacity to think and act collectively and cooperatively. This perspective is also of applicative interest for those who design technological systems to support working practices, and who have come to realize that many failures in the introduction of new technologies are due to simplistic representations of the activities that they are intended to support. The resumption of ethnographic studies on work is also due to 
the interest of information system designers in 'thick' descriptions able to unveil the aspects of collectively performed working practices.

The literature on practice is rather extensive and often common sense understanding of practice - as opposed to theory - is prevalent. Practice is a polysemic concept and Gand and Jensen (2014, p. 698) notice how 'practice' can refer to a location or it can refer to action. It is possible to be 'in practice', to 'have a practice' or to be 'constituted by practice'. Therefore, practice can be a cause, an effect or an explanation.

According to Sandberg and Tsoukas (2015) we can distinguish three approaches to the study of practice: commonsensical theories of practice, general theories of practice, and domain-specific theories of practice. The first notion of practice typically reflects a commonsensical understanding of the term as simply 'what people do'; the second characterizes general theories of practice that provide a comprehensive conceptualization of practice (as Bourdieu, Giddens or Schatzki), and the third includes several domainspecific theories, as a performative approach to routines (Feldman and Pentland, 2003), understanding strategy as practice (Vaara and Whittington, 2012), a stucturationist approach to technology (Orlikowski, 2000), and a practice-based view on organizational knowledge and learning (Gherardi, 2006; Nicolini et al., 2003; Sandberg and Pinnington, 2009; Tsoukas, 2011).

In my opinion, the commonsensical understanding of practice is not useful, the second is too abstract for guiding the empirical analysis of practices in their diversities, and therefore we have to expect in the future a development of more specific theorizing of practice in relation to different domains. The number of domain-specific theories of practice is growing fast and it is not my intention to review them here, rather I wish to make explicit that the approach that I am developing in this book can be identified within the third understanding of the term 'practice' within organizational knowledge and learning (Gherardi, 2011) and specifically that its starting point is knowing as a situated activity. However, as 'practice' is a polysemic term, the difficulty in focusing on how the authors define it is mainly due to two ways of understanding practice.

With reference to scientific practices Rouse (2002, p.161) argues that there are at present two fundamentally different conceptions of practice:

1. practices identified with regularities or commonalities among the activities of social groups;

2. practices characterized in terms of normative accountability of various performances.

According to the first conception, practices are commonly defined in terms of 'arrays of activities' which form patterns, nexuses or bundles 
(Schatzki, 2005). Undoubtedly a practice consists of a set of activities, however this is not the most salient element for its definition. Whilst it certainly makes sense to analyse practices in terms of patterns in the activities that constitute them, if we restrict the analysis to this level we lose sight of what makes a practice recognizable to its practitioners, and of why practices continue to be repeated, that is, practised.

The second definition has an edge on the former because it directs attention to practices defined as 'ways of doing things together', and therefore to the social processes that support practices ethically, aesthetically and emotionally. For example, Rouse (2001, p.199) writes: 'actors share a practice if their actions are appropriately regarded as answerable to norms of correct or incorrect practice'. This signifies that, within every community of practitioners, discussing and disputing practice, developing different cultures of practice yet identifying with a shared practice, and making practice into terrain legitimately contestable by its practitioners, are dynamics that socially sustain a practice. These dynamics construct the conditions in which the practice is reproduced. They can be conceived as the everyday work of practice reproduction, and as the dynamic work which adapts the practice to changed circumstances, so that it is once again performed 'for another first time' (Garfinkel, 1967, p. 9).

\subsection{AN ORDINARY PRACTICE OF THE GIG ECONOMY}

Work is much more than an activity undertaken in order to achieve a predetermined purpose. To familiarize the reader with this idea, Box 1.1 presents a brief description of the workday of Marco, an express delivery courier (Tiddi, 2002, pp. 37-9). Marco epitomises the gig economy (Murgia et al., 2016) and the precariousness embedded in his working practice illustrates the plurality of reciprocally interacting elements of a practice, as well as the economic and institutional context in which such a practice is embedded.

The example shows how achieving a simple goal (delivery of a package) requires complex abilities and involves the entire person. First, Marco is involved with his body: travelling from one side of the city to the other forces him to breathe car exhaust fumes, weave through the traffic on his scooter and take comfort from the fact that at least it is not raining and not too cold. His five senses are therefore 'at work' and his body receives diverse aesthetic perceptions that contribute to increasing (or decreasing) 'pleasure' gained from performing the activity. Marco's communicative and relational abilities are also part of his body, so that he knows that politeness is one of the modes of interaction required by his job, and that 


\section{BOX 1.1 THE PONY EXPRESS WORKING PRACTICE}

Marco is sitting on his scooter, his radio transmitter at his ear, waiting for a call from the express delivery depot. He has asked for details about an address given to him. He wrote it down as he always does, but now he cannot find it. 'This happens when you're in a hurry,' he thinks. Marco has worked as an express delivery courier since he was made redundant by his previous employers. He waits, but he knows that he will not have to wait long: with Christmas approaching, there is a lot of business, and the office is under pressure. The answer soon arrives, and he is given the details he needs. Addressee: Service \& Co. Marco looks at what he has just written down. He realizes he cannot remember where the street is. He fishes the Rome city map out of his scooter trunk. He looks for the street and finds it: it is on the other side of the city. He thinks, 'I've got to get across the whole of Rome, and at this time of the year the streets are murder even when you're on a scooter. When you get long-distance deliveries like this one, you feel like leaving them at the depot ... but then you get on with it ... It's obviously that the easiest deliveries go to the older guys. You can't cause problems, because if you do, they won't give you work. The only solution is to be ready to deal with hassles as quickly as possible. At least, let's hope I get a tip. But if I take the ring road, it's gridlocked at this time of day. And then I might be fined, because you can't ride a scooter on the ring road. l'd better go through the city centre, enter the restricted traffic zone, where the traffic wardens can't be bothered with scooters even if they're not supposed to enter.' Marco starts up his scooter and sets off. He dodges the traffic wardens, crosses the city centre, and heads for Nomentana. He reaches his destination. Macro thinks 'l've inhaled so many exhaust fumes it's like I've smoked a packet of fags, but the weather's been good. It isn't raining and it isn't cold. It doesn't even seem like winter. Here we are, street number 32.' Marco parks his scooter and approaches the intercom. He looks for the name of the firm, finds it, and rings. A girl answers. 'I have a package for Service \& Co.' he says. The girl buzzes him in. 'Third floor', she says. The lift is out of order. Marco walks up three floors, finds the door and rings the bell. The door opens automatically. Marco enters. He goes to the girl seated in the lobby, gives her the envelope, and gets her to sign the receipt. He lingers for a moment, hoping for a gesture from the girl, but she does nothing. 'So there's no chance of a tip. l'd better be polite otherwise the management will be on my neck. That's all I need,' he reasons. He bids the girl goodbye. Marco looks at his watch: 'I told Lella that l'd get off at five, I can still do another one.' He goes back to the depot to pick up another delivery.

Source: Tiddi (2002, pp.37-9).

the absence of a gesture by the girl who took delivery of the package meant that he would not receive a tip. This prompts reflection on how such modes of interaction (what Hochschild, 1983, called 'emotional labour') are not specific to the work of an express delivery courier but relate to broader social practices which impact on (and are reproduced by) everyday work relations. 
Second, Marco is also at work with his mind, given the cognitive labour required to deliver the package. What is the exact location of the company? What route should he take to get there? We see from how Marco answers these two questions that cognitive labour does not follow an abstract logic but draws on situated knowledge. Marco uses the street map to find the exact location of the company, but he decides which route to take by relying on his personal knowledge (and experience) of traffic and road conditions. Hence, the knowledge which Marco applies is knowledge that he has acquired from his everyday experience, and which he must mobilize because it comprises the practical solution to his problem.

However, it would be over-hasty to conclude that the success of Marco's work depends solely on his personal abilities and that it is entirely individual. He is in fact in contact (by radio) with an operations centre which gives him the delivery coordinates, and to which he can refer when some unforeseen event occurs (such as losing the recipient's address). Thus, one understands that Marco's work also depends on (and impacts on) that of others, and that in general it requires the coordination of multiple activities in different times and places (the depot which receives the delivery order, communication of the address to the courier and delivery by the latter).

Moreover, Marco's world is populated not only by human actors but also by algorithms, technologies and objects. The radio transmitter (which connects him to the operations centre), the scooter (which gives him mobility), the lift (which is out of order), the receipt (which certifies delivery), are all elements of differing technical complexity intrinsic to Marco's work and which can help or hinder its performance. For that matter, the automatism of the gesture with which Marco extracts the street map from the trunk on his scooter is enough to evoke the pervasive role of objects in any practical activity.

The working practice of an express delivery courier therefore takes place within an ecology of intimately connected elements: the body, language, prior knowledge, and the human and nonhuman actors that everyday activities bring together. Moreover, it is supported by background knowledge, by the tacit rules of the community of practice to which Marco belongs (the reason why 'the easiest deliveries go to the older guys'), as well as by the historical, institutional and cultural context in which the work takes shape. In fact, like many other jobs in the so-called 'gig economy', Marco's job is marked by precariousness and an unstable position in the labour market, but it is important to note that this does not diminish the value of such jobs evidently rich with knowledge. Thus, through Marco's story we have seen the duality of practice: as a knowledgeable doing that connects humans and nonhumans and as the effects of that recursive 'doing' that identifies one of the practices of the gig economy. 
Another interesting story about the emergence of a practice as a form of collective action is 'bike commuting' (Wilhoit and Kisselbourg, 2015). Bike commuting to work is not usual in US, where it cannot be considered a social practice in the strict sense. Bike commuters constitute themselves as a collective through individual material and spatial practices, creating possibility for change. However, bike commuters' discourses indicate that they do not experience a collective identity or sense of community of practice. The authors use their study of bike commuting to illustrate two areas of theory, relevant also for practice-based studies. First, they suggest that collective action can take place without organization or explicit organizing: individual activities can aggregate to have an effect even if they are not officially coordinated or members do not acknowledge membership in a collective. Second, they suggest that the material can constitute a collective, even without human, discursive recognition of it.

New social practices may emerge from individual activities, without a collective subjectivity, and without being coordinated. If we think of places accommodating freelance workers, in the creative industries and elsewhere, we can see how practices have become so fluid (thanks also to technology) that they transcend location, even if space and practice reflexively constitute each other (Cnossen and Bencherki, 2018). It is precisely their reflexive relation that contributes organizationality (Dobusch and Schoeneborn, 2015) even to collectives that do not think of themselves as organizations.

The creative and the green economy may host many examples of the birth of new practices, but also consumption studies offer good stories of the material constitution of new practices, such as the story of the diffusion of the 'Nordic walking' invention (Shove and Pantzar, 2005). We may conclude that while people work in a material-discursive environment, they perform activities of different kinds: they produce and reproduce society. We may also say that there is work that is necessary for a person to be able to work and to be able to accomplish keeping a practice on its tracks.

\subsection{KEEPING A PRACTICE ON ITS TRACKS}

It should always be borne in mind that working and spending a part of the day engaged in work is only one aspect of life, for life is also made up of other activities which usually interweave with the routine of work. Recall, for instance, that Marco the express delivery courier thought about his date with his girlfriend, and took decisions about his practical activities considering other activities not related to work. In fact, a working practice is intertwined with other social practices both because together they 
perform sociality and because 'the social' is made up by 'relational work' (Gherardi, 1990), the purpose of which is to maintain and reproduce everyday sociality, both within the workplace and externally to it, with other social relations.

Relational work, moreover, is not the only work performed alongside work as a change-directed activity. Together with the latter, a large amount of work is undertaken so that activities may proceed smoothly. This is 'articulation work', a term used by Strauss (1988) and by Corbin and Strauss (1993) to denote the work necessary to establish, maintain and change the arrangements necessary to work both within one's own organizational unit and among different units. Susan Lee Star brought this approach to bear on the problem of designing information technology for workplaces (Star and Strauss, 1999). She argues that work practices cannot be meaningfully modelled by means of predetermined, formal work flows and task descriptions. Rather what keeps a practice going is the often-invisible work of articulation, that is, ongoing negotiations about the nature of the tasks and the relationships between individuals in the organization, by ad hoc reactions to upcoming contingencies, by distributed decision-making, by 'multiple viewpoints' and 'inconsistent and evolving knowledge bases' (Gerson and Star, 1986, p. 266). Articulation resolves these inconsistencies by packaging a compromise that 'gets the job done' despite local contingencies or inadequate knowledge of local circumstances.

Hospitals, for instance, are workplaces in which a very extensive set of people interact to perform many different practices whose accomplishment requires supplementary articulation work. If the nursing staff are to do their work, they must work in conjunction with the doctors in the ward and with other departments (the pharmacy, the kitchen, the operating theatres, the analysis laboratories and so on). Without these collaborative agreements, the nursing staff cannot be sure that medical schedules are updated and available to each shift so that the requisite medicines are present in the correct department, that the patients are fed and treated, the wards are clean, and the technologies are working. The set of these interactions are customarily established within the units and among them through a series of collaborative and competitive strategies that require negotiation and persuasion; but once established they do not last forever and are often interrupted (or disrupted) by unexpected events, breakdowns or contingencies requiring further articulation work. Such a dynamic has often been observed in the case of collaborative projects across different professional cultures (Bruzzone, 2019; Marshall, 2014, Tagliaventi and Mattarelli, 2006) and it characterizes much of project-based working, knowing and thinking. 


\section{BOX 1.2 THE HOSPITAL WARD CASE}

During an afternoon shift, a hospital pharmacy found itself short-staffed because two pharmacists had taken sick leave. Moreover, during that shift, several medical emergencies had occurred and to which the pharmacy had to give priority. As a consequence, medication which should have been sent to a unit arrived too late for it to be administered during the afternoon shift. Because the doctor was anxious that the patient should receive the treatment, the nurses on the afternoon shift made arrangements with those on the night shift for the latter to administer the medicine. However, the treatment required that the patient be kept under constant observation while the medicine was being administered (intravenously). Because there were fewer nurses on the night shift than in the afternoon, the night-shift nurses assumed an attitude of resentment and frustration. They did not have the power to request more personnel; nor could they choose whether or not to administer the medicine ordered by the doctor. They discussed the tardiness of the afternoon-shift nurses in starting the treatment: why had they waited? Why had one of them not gone personally to the pharmacy to fetch the medicine? The afternoon-shift nurses tried to explain that the delay had not been their fault. In the end, the nurses on the night shift had to include this task on their schedule. But the next morning, when reporting to the head nurse, they complained vociferously about what had happened. The head nurse had to investigate the causes of what had happened, make peace between the two shifts, and reply to the doctor's protests that the treatment had not been administered in due time.

Source: Corbin and Strauss (1993, pp. 74-5).

When unexpected events occur, the work is delayed, it is of poor quality or it is simply not done. This produces conflicts, anxieties, frustrations and further repair work on the social relationships that have been unintentionally severed. The normal and quotidian breakdowns in normality therefore require work which repairs and renegotiates previous arrangements.

An example of articulation work in response to a contingent event is provided by Corbin and Strauss (1993, pp.74-5) and is described in Box 1.2.

What does this example tell us about practice? It shows that the execution of work is a collective and coordinated action. It is not enough that the work has been divided among specialized and coordinated tasks, that division must be constantly and cooperatively reproduced. Because there are so many different types of activities, it is necessary to agree on what must be done, to what standards, in what places, with what resources, with what counterparts and so on: all this constitutes articulation work. But these agreements must be reached, maintained and revised through a constant process comprising diverse interaction strategies, like negotiation, discussion, education, persuasion, threat or coercion. 
Corbin and Strauss (1993) propose three concepts with which to analyse articulation work:

1. The arrangements made among people in the same operational unit or among different units. These are agreements reached on the actions necessary for performing each practice. For instance, within a particular unit, agreement is reached on what is to be done, by whom, with what resources, for how long, for what purpose, to what standard; among different units, agreement is reached on resources, technologies, execution times, spaces, competences and so on. The arrangements are always temporary and subject to re-negotiation, and it is for this reason that articulation work is necessary in accomplishing a practice.

2. Working things out: that is, the strategies of interaction by which arrangements are made, maintained and revised. These are interaction strategies in response to what has been said or done by others, before the work starts and during the arrangement-making process. Possible strategies are negotiating, reaching compromises, discussing, educating, persuading, dominating, threatening.

3. Stance: that is, the position assumed by each participant towards both the work and the process of working things out. It therefore concerns each participant's perception of his/her capacity to control and influence the situation and context in which the arrangements are made. Individual stances also depend on (and change) the stances of others.

The concept of 'articulation work' well expresses the set of activities necessary to accomplish a working practice. But besides this concept, there are several others which are variants of it. To be stressed in particular is the importance (especially in service jobs) of arbitrages (Grosjean and Lacoste, 1999) when agreement must be reached on values, orders of magnitude and the action appropriate to the situation; in short, cases in which the deontological dimension of the profession is called into question (as often happens in hospital settings or in relation to care and service jobs). The collective production of values-based rules of behaviour is therefore a dimension of work, in that social groups produce, legitimate, observe, negotiate, comply with or disregard the rules while people work and deal with practical problems.

Another concept which can be associated with the previous ones is that of knotworking, developed by Engeström (1999b, p. 31) to recall (and oppose) the idea of networking. The expression suggests that it is not sufficient to create relations; these must then be fixed - knitted together - and made relatively long-lasting, also by means of objects or ad hoc solutions. 
This therefore requires collaboration which constructs temporary organizational relations, and which involves (for instance) customers, producers and reciprocal learning among the parties engaged in the solution of a problem, and so on. Knotworking (Engeström et al., 1999) is a selforganized activity based on the practical knowledge of those who discern and resolve a problem.

Finally, we should also consider the communicative dimension of articulation work. The concept of articulation has a specific connotation as discursive articulation. It is defined as 'the construction of nodal points which partially fix meaning' (Laclau and Mouffe, 1985, p. 113). The concept of articulation (together with sedimentation) has been elaborated within discourse theory in order to account for the relative stability of the social. Over time, discourses achieve an 'objective presence' (Laclau, 1990, p. 34), despite being forged by a radical contingency that tends to conceal its historicity and situatedness. In fact, discursive articulation may constitute a communication practice that upsets and disturbs sedimented discourses that can be problematized in new articulations through a process of reactivation that unsettles their potential degrade. A practice may change also thanks to a different articulation of the discourse on it (Gherardi, 2012b).

What people do when they work, therefore, is much more complex than the simple execution of a planned activity. We can consequently explore what is meant by work as a situated activity in light of the intellectual history of what has been called the 'paradigm of situated action'.

\subsection{PRACTICE AND THE PARADIGM OF SITUATED ACTION}

In 1994 the French journal Sociologie du Travail devoted a special issue, edited by Anni Borzeix (1994), to the theme 'Work and Knowledge'. ${ }^{3}$ The monograph had the merit of bringing together the North American, English and French schools, and of anticipating the developments thereafter which gave rise to the body of inquiry known as 'practice-based studies'. In 2000 and in 2002 two other special issues appeared (see Gherardi, 2000; Heath and Button, 2002) and when we compare their list of articles, shown in Table 1.1, we can easily see an ongoing conversation at distance among authors who share similar concerns. Behind the names of the authors we can read the influence of ethnomethodology (Lynch, Cicourel), distributed cognition (Hutchins), activity theory (Engeström; Blackler et al.), workplace studies (Heath and Luff), Actor-Network Theory (Latour; Law; Gherardi and Nicolini), and situated learning theory (Wenger; 
Table 1.1 Comparison between the first three special issues related to practice-based studies

\begin{tabular}{|c|c|c|}
\hline $\begin{array}{l}\text { SOCIOLOGIE DU } \\
\text { TRAVAIL }, 1994\end{array}$ & ORGANIZATION, 2000 & $\begin{array}{l}\text { THE BRITISH } \\
\text { JOURNAL OF } \\
\text { SOCIOLOGY, } 2002\end{array}$ \\
\hline Editor: Anni Borzeix & Editor: Silvia Gherardi & $\begin{array}{l}\text { Editors: Christian Heath } \\
\text { and Graham Button }\end{array}$ \\
\hline Aaron Cicourel & Etienne Wenger & $\begin{array}{l}\text { Lucy Suchman, Randall } \\
\text { Trigg and Jeanette } \\
\text { Blomberg }\end{array}$ \\
\hline Edwin Hutchins & Dvora Yanow & $\begin{array}{l}\text { Christian Heath, Paul } \\
\text { Luff and Marcus Sanchez } \\
\text { Svensson }\end{array}$ \\
\hline $\begin{array}{l}\text { Barnard Conein and } \\
\text { Eric Jacopin }\end{array}$ & $\begin{array}{l}\text { Alessia Contu and Hugh } \\
\text { Willmott }\end{array}$ & Michael Lynch \\
\hline Dominique Vellard & $\begin{array}{l}\text { Frank Blackler, Norman } \\
\text { Crump and Seonaidh } \\
\text { McDonald }\end{array}$ & $\begin{array}{l}\text { John Hughes, Mark } \\
\text { Rouncefield and Peter } \\
\text { Tolmie }\end{array}$ \\
\hline $\begin{array}{l}\text { Christian Heath and } \\
\text { Paul Luff }\end{array}$ & Yrjo Engeström & $\begin{array}{l}\text { Jack Whalen, Marilyn } \\
\text { Whalen and Kathryn } \\
\text { Henderson }\end{array}$ \\
\hline $\begin{array}{c}\text { Jacques Theureau and } \\
\text { Geneviève Filippi }\end{array}$ & Lucy Suchman & $\begin{array}{l}\text { Daniel Neyland and Steve } \\
\text { Woolgar }\end{array}$ \\
\hline Isaac Joseph & $\begin{array}{l}\text { Silvia Gherardi and } \\
\text { Davide Nicolini }\end{array}$ & $\begin{array}{l}\text { Graham Button and Wes } \\
\text { Sharrock }\end{array}$ \\
\hline Bruno Latour & John Law & Randy Hodson \\
\hline
\end{tabular}

Suchman et al.). When taken together these ideal conversations have in common an interest in knowledge as something people do together and knowing as a situated activity.

The special issue of Sociologie du Travail contained an illuminating article by Barnard Conein and Eric Jacopin (1994), which reconstructed the intellectual roots of the concept of situated action and connected it with subsequent developments. We shall refer to this article to show that the interpretative framework of situated action draws on the thought of Alfred Schütz (1962) and George Herbert Mead (1934) - that is, on interactionist approaches. We owe to these two authors (and to phenomenology and pragmatism in philosophy) the idea that situated action is anchored in space and time. Both of them emphasized that all work presupposes a self-referred space made up of objects. They also stressed that contact with (and manipulation of) objects is the support for the execution of work. 
Schütz (1962) described work as 'the world within my reach', as an activity which both depends on the context and constitutes it. Mead (1934) drew a distinction between the object within range of manipulation (what can be seen and touched) and the object at a distance, out of reach but present in the visual field. He thus showed that the space of work is progressively created through manipulation with tools and objects. Manipulatory activity presupposes the reciprocal construction of space and action, because action (bringing objects 'within reach') marks out the boundaries of the same space that it thus constructs.

This idea was taken up by cognitive ethnography (Lave, 1988), which acknowledged that cognitive activities are not solely mental but also rely on the material elements in the context which anchor the necessary information supports. When Jean Lave and colleagues (1984) studied arithmetic calculations in supermarkets, and how the arrangement of purchases in trolleys reproduced the order of the aisles in which the goods were displayed, they showed how the spatial environment gives shape to situations, and how our 'practical arithmetic' follows rules different from those learned at school. Situated learning theory (Lave and Wenger, 1991) was developed on an understanding of learning as competent participation in practices and the embeddedness of learning practices in power relations. As Barnes (2001, p. 28) puts it, 'to engage in a practice is to exercise a power'.

Calculation by adults in work situations follows a situated logic which uses visual supports and aids devised in relation to the context. Objects help us remember, measure and compare. A pile of files on the desk is an indicator of the amount of paperwork still to be done and the amount of time that it will take (Bruni, 2005). In a similar manner, Beach (1988) has shown how bartenders use the shapes and places of glasses, as well as the colours and quantities of liquids, as reminders - anchored in the environment - of how to prepare cocktails. A context is not a container of practices; rather, practices create their own context (Fox, 1997). The workplace is an active context: it helps us remember; it allows us to do some things and not others (for example, those that might put our safety at risk); it solicits our action with visual or auditory signals; it furnishes programmes that help us diagnose possible breakdowns and suggests how we should intervene.

The situated action approach extends the original idea of work as interaction to encompass action with objects in relation to the physical environment and situations. The aim of the approach and its research methodology is to understand how work environments, equipped with artefacts and objects, may significantly facilitate the performance of tasks by those who work in those settings. This theme includes characterizing experience at a fine-grained level, understanding the role of the context in 
which learning occurs; characterizing organizational learning processes, and analyzing knowledge creation, retention and transfer (Argote and Miron-Spektor, 2011).

The first lesson taught by the paradigm of situated action is that the context is not a mere container but rather a resource for action; the second lesson is that the term 'situated action' has a privileged relationship with the idea of the 'Other' (first introduced by Mead) and with Goffman's theory that ties it to communication. In fact, Erving Goffman $(1956 ; 1959)$ developed a theory of situation using the terms 'situated activity system' or 'encounter'. When two people communicate, they reciprocally make an attention space manifest, and therefore accessible, and their action is situated because it is oriented by and dependent on the action of the recipient of the communication. The situation is the result of the interaction between those two people. As Lave (1991) notes, one should bear in mind that 'situation' is not simply another term for the immediate, physical context. A situation has to be explored in social and historical terms. The roots of situational analysis in practice-based studies (Clarke et al., 2016) have to be found in this cultural milieu.

'Situated action'4 became a well-recognized concept through the work of Lucy Suchman $(1987$; 2007) who resumed Goffman's theory in one of her books (significantly titled, Plans and Situated Action) and asked whether the concept of interaction may be extended to machines, or whether interaction presupposes communication among humans.

In other words, plans (or programs) for machines are not plans for people. During the 1980s, plans attracted a great deal of research, especially in robotics, but the criticism brought by Suchman $(1987$, p. 4) was that:

The behavioral science and commonsense that supports the design of interactive artifacts treats a plan as something located in the actor's head, which directs his or her behaviour. In contrast, this study adopts a view of plans just as formulations of antecedent conditions and consequences of action, which account for action in a plausible way.

Before action, plans have only a predictive or organizational purpose; after action, plans serve to justify the actions undertaken. An example provided by Suchman is canoeing down a river. Before setting off, the canoeist may plan a course for descending the river, but when he/she reaches the rapids, he/she sets the plan aside and resorts to all his/her skills. Hence a plan is an ingredient of practical action, in the sense that it is an artefact that helps one to reason on the action, but it is not a mechanism generative of the action.

Generally, therefore, describing an action as 'situated' means considering the organization of the action as emerging in situ from the dynamic 
of the interactions. This dynamic results from two processes: (1) each participant's understanding of the action of the other or others; (2) the perception and interpretation of the signals emitted by the surrounding environment.

Central to the paradigm of situated action is a revised conception of context as no longer a container of action but a situation in which the interests of the actors and the opportunities in the environment meet and are reciprocally defined. Of central importance in work, therefore, are interactions with others, situated communication, the construction of situations, the relationship with the physical environment and the objects in it, but especially the idea that these elements are 'held together' and express a contingent logic embedded in the situation.

We shall see later how the term 'situated' is deeply grounded in feminist theorizing about knowledge (Haraway, 1991) and the positioning of researchers in epistemic practices (Chapter 10). For the time being, however, we shall consider the theoretical link leading from the notion of working practice as situated action (which characterized the 1990s) to the notion of practising as knowing-in-practice.

\subsection{WORKING PRACTICE AS KNOWING-IN-PRACTICE}

The concept of 'community of practices' first arose within analyses of organizational learning as the precursor to studies on practical knowledge (Easterby-Smith et al., 2000) and how it is created, disseminated and conserved in working practices and in the community that forms around a practice (Karataş-Özkan and Murphy, 2010). Numerous authors (Brown and Duguid, 1991; Lave and Wenger, 1991; Wenger, 1998; Zucchermaglio, 1996) have identified the community of practice as an informal aggregation defined not only by its participants but also, and especially, by the way in which these act and interpret events. For example, situated learning theory puts forward a theory of knowledge acquisition in which 'knowing is inherent in the growth and transformation of identities and it is located in relations among practitioners, their practice, the artefacts of that practice, and the social and political economy of communities of practice' (Lave and Wenger, 1991, p. 122). Knowledgeability thus emerged as a central concept within the evolution of the community of practice approach (Omidvar and Kislov, 2014).

A community of practice is a network of relations among people, activities and the surrounding environment, in constant communication and interaction with other communities. The relations are constructed around activities, 
and activities take shape through social interactions, so that specific competences and experiences become part of the individual and are stabilized within the community. Practitioners' ongoing engagement in social practices and their reproduction of the knowledge generated and kept in those practices is how they reconstitute knowledgeability over time and across situations. Of interest are the ways in which knowledge is transmitted from one community to another: how new conversations develop between them and how the interdependence among activities creates opportunities for innovation through the hybridization of conversations. This theoretical background - developed mainly by Brown and Duguid (1991) - has given rise to the idea of practices as loci of learning, organizing and innovating. Rather than asking what kinds of cognitive processes and conceptual structures are involved, researchers ask what kind of social engagements and material settings provide the proper context for knowing, working, learning and innovating (Brown and Duguid, 2001). Afterwards the concept of community of practices was turned upside down (Gherardi, 2009a) in that of 'practices of a community' to emphasize how practices were to form the collective subject, rather than assume it, and practices have been termed 'sites of knowing' (Nicolini, 2010) to underline the non-distinction between knowing and practising.

I introduced the term 'knowing-in-practice' (Gherardi, 2001, p. 134) to move away from the mental and individual image of knowledge to consider it as an enactment. This assumption prompts the question: is it possible to observe knowledge as it unfolds and describe it empirically without resorting to concepts such as the intentionality of actors, with their mental and/ or linguistic representations, and without having to rely on what actors say that they think? In other words, can practical knowledge be described as a situated activity, and as an activity of joint and collaborative production between humans and nonhumans, without having to attribute priority to the former, and without assuming that knowledge precedes action?

The contribution of the concept of 'knowing-in-practice' in answering these questions is that not only is it possible, it is also useful to describe knowledge as a practical accomplishment which does not require investigation of what goes on in people's minds and of what they say that they think. At the theoretical level, the entry of the concept of knowing-inpractice into the literature on practice theories has helped to displace the mind (meanings, values or truth) as the central phenomenon in human life and to prioritize practices over individual subjects. Consequently, when the locus of knowing and learning is situated in practice, the focus moves to a social theory of practice that addresses activity and passivity, the cognitive and the emotional, mental and sensory perception as bits and pieces of the social accomplishment of knowledge and of the social worlds in which practices assume spatiality and facticity. 
When Wanda Orlikowski (2002) used the term 'knowing-in-practice' to explore empirically a geographically dispersed high-tech organization (Kappa), she used the lens of distributed organizational knowing to understand how members of global product development organizations generate and sustain knowledgeability in their distributed operations. She identified five practices enacting specific forms of knowledgeability. The first two of these practices, sharing identity and interacting face-to-face, enact a knowing of the organization and the players in it. The next three practices, aligning effort, learning by doing, and supporting participation, constitute knowing how to coordinate on complex projects, knowing how to develop capabilities for doing product development, and knowing how to innovate within global operations. For Kappa members, these five kinds of distributed knowing in organizing generate a knowing how to be consistent, competent and creative across a variety of technical, geographic, historical and cultural boundaries.

Within education studies, and at the same time, the term 'knowing in practice' appeared (Billett, 2001) in order to question the relationships between social practice and individuals acting in social practice. This view of knowing in practice is quite distinct from those suggesting that domains of knowledge required for performance are objective bodies of knowledge, such as an academic discipline. Situational factors associated with the expert enactment of knowledge go beyond the possession of sociocultural technical skills and tools (cutting hair, diagnosing a patient). Instead, these factors influence how these skills are manifested in a particular circumstance: an acceptable practice in one workplace may be quite inappropriate in another, as procedures are different and the goals for performance may be quite distinct. These factors influence not only the activities individuals engage in, but also what is taken as expert performance. The construction of the individuals' domains of vocational practice is constituted reciprocally through their participation at work.

To convey a preliminary idea of the theoretical and methodological framework in which working practices are analysed as knowing-in-practice, we may say that knowledge can be seen and analysed as an activity, rather than as an object (a body of knowledge), and that it can therefore also be studied as a situated activity. In other words, knowledge emerges from the context of its production and is anchored by (and in) material supports in that context. We may also say that knowing is an activity both individual and collective; that it is an activity situated in working practices; and that, therefore, practical knowledge is contextual as opposed to being decontextualized and theoretical.

A metaphor which aptly illustrates how a practice emerges and is 
socially and materially sustained is that of climbing, as described by Hennion (2007, pp. 100-101):

\begin{abstract}
What climbing shows is not that the geological rock is a social construction, but that it is a reservoir of differences that can be brought into being. The climber makes the rock as the rock makes the climber. The differences are indeed in the rock, and not in the 'gaze' that is brought to it. But these are not brought to bear without the activity of the climb which makes them present. There is coformation. Differences emerge, multiply and are projected. The 'object' is not an immobile mass against which our goals are thrown. It is in itself a deployment, a response, an infinite reservoir of differences that can be apprehended and brought into being.
\end{abstract}

Hennion thus illustrates the relationship of co-formation between sociomateriality and identity, but he only alludes to the fact that the same relationship exists between the doing - climbing - and the knowing: that is, knowing how to read the rock, seeing the handholds that become such only at the moment when the climber sees them and makes them handholds for his/her next move. This knowing how to read the context as a 'reservoir of differences', knowing how to identify the handholds for the next action, knowing what the next action will be (Garfinkel's, 1996, 'what next'), and possessing the vocabulary to talk competently about climbing, are things that are collectively learned, transmitted and transformed during practice, and as an effect of it.

To work is therefore to use a set of knowledges as resources for action, and working produces further knowledges. Working is knowing, therefore, and not simply applying acquired knowledge. And, as we shall see, knowing is a collective knowledgeable doing, and by focusing on knowing rather than knowledge, the distinction between knowledge and learning is blurred.

The shift from knowledge to knowing allows its analysis in terms of a phenomenon that according to Blackler $(1995, \mathrm{p}$. 1039) is: (a) manifest in systems of language, technology, collaboration and control (that is, it is mediated); (b) located in time and space and specific to particular contexts (that is, it is situated); (c) constructed and constantly developing (that is, it is provisional); and (d) purposive and object-oriented (that is, it is pragmatic).

Consider, for example, the practice of cardiological teleconsultancy in order to appreciate knowing as an ongoing practical achievement when working at a distance. The general practitioner records the patient's ECG with a portable apparatus. The recordings may be made at the doctor's surgery or in the patient's home because the apparatus can store around ten traces that can be transmitted at a later time. The call centre 
coordinates the referral procedure, establishing contacts between GPs and cardiologists, and handling transmission of the ECGs. The traces are sent by the doctor, downloaded using special software at the call centre, and distributed to the cardiologists, who can read them on their PC screens. The traces are discussed by telephone with the GPs and then sent back to the GPs by fax with the report attached. The GPs usually send the trace immediately after recording it and use the remote consultation service while examining the patient.

The service almost takes the form of a 'cardiological examination at a distance', and the activity which emerges from this new workplace distributed in space is substantially different from already existing medical practices: it is neither a cardiological examination nor a general one; it is not a simple consultation between experts or a training exercise within a course. Teleconsultancy, therefore, is a new kind of medical practice, a sort of hybridization of already existing practices which obliges the two experts to learn new modes of work and action in the social, but also material, context in which they are embedded. The distributed setting made possible by the new technologies requires the two experts to learn how to act in a sociomaterial environment characterized by different types of knowing distributed among different actors, objects and relations. To practise telemedicine is therefore to activate a knowing-in-practice that indeed involves the medical knowledge acquired at university and refined through working experience but does not consist merely of the application in a situation of already existing knowledge.

Box 1.3 presents what can be considered a typical telephone call. The telephone call reported shows that, when the ECG and the patient do not align (the ECG is normal, but the patient feels ill), various elements are discursively mobilized, and the trace moves into the background, losing its status as a privileged object. To paraphrase Latour (2002), it is as if the trace has become a 'labyrinth' through which the two doctors must find their way. Thus, previous ECGs, reports on other examinations, medications, family histories, become elements that must be discursively activated and aligned in order to restore meaning to the situation. The cardiologist and the GP seem almost to be suggesting interpretations to each other, as in a dance where two actors must lean on each other to find a point of balance which permits their movement. The action of the cardiologist and the GP, in fact, does not take place in an empty space, but internally in a broader medical practice. It is consequently to the broader medical practice that they turn in the absence of points of contact between patient and ECG.

From a methodological point of view, a sociologist who studies a practice as knowing-in-practice wonders what anchors the distributed 


\section{BOX 1.3 THE TELECONSULTANCY CASE}

\section{[Greetings.]}

GP: I've had this ECG done on a patient already affected with chronic ischemic cardiopathy, because he felt ill while he was eating, he felt faint and a weight on his stomach.

C: The trace doesn't seem ... how is he now?

GP: He's lying down now ... he feels weak ... he hasn't got dyspnoea, absolutely not ... he still feels this weight ... I think it's indigestion, I mean, he needs to vomit ... but, you know . . I I preferred to do the ECG ...

C: l'd say ... there aren't any evident alterations ... of course, then you have to look at the clinical (assessment) . . . because these things, sometimes ... these things are a bit tricky ... For the moment l'd keep an eye on him ... there's a left axial deviation . . . there's . . . some ventricular extrasystole . . . Is he taking Cardioaspirin?

GP: No, in fact I wanted to give it to him ...

C: But he has a history of ischemic cardiopathy, but he hasn't had acute episodes?

GP: No, no. Perhaps ... five years ago, there was something ... when the chronic ischemia diagnosis was made...

C: l'd wait a bit longer... how old is he?

GP: 85.

C: The risks are clearly there, if the thing doesn't sort itself out, l'd have him looked at, just to be on the safe side . . . but, at the moment the trace doesn't show anything...

GP: ... out of the ordinary ...

C: $\quad \ldots$ although traces can sometimes be negative ...

GP: ... right ... in fact ... that's true, you can't always rely on the trace ...

C: $\quad .$. no, no there's a good percentage of heart attacks with normal traces ... except that this .... well ... I mean ... at 80 years old, of course, some problem always comes out!

GP: Yes, l'll give him an antacid and then we'll see.

[Salutations.]

Source: Bruni et al. (2007, p. 93, reprinted in Gherardi and Strati, 2012, p. 104).

and fragmented knowledge that gives form to the teleconsultancy. $\mathrm{He} / \mathrm{she}$ establishes that it consists of:

1. The patient. The patient possesses, and contributes to the teleconsultancy, knowledge about his body and sensations. In this case, knowing consists in the ability to perceive an 'anomaly', translate it into an account through language, and narrate the symptoms to the doctor. This preliminary description and bodily knowledge is supported 
by the general practitioner, who translates the patient's subjective knowledge (which medicine assumes to be strongly influenced by individual factors and therefore unreliable) into elements of 'scientific' knowledge through its 'translation' into medical terminology.

2. The medical community. The doctor's expert knowledge is expressed in the transformation of the patient's idiomatic and colourful expressions into an 'objective' knowledge through the systematic use of medical terminology and the application of medical expertise to common sense (Cicourel, 1982). In the above telephone call, it is noticeable that the two doctors exchange their opinions on the reliability of the trace representing the patient. Doing so is not only functional to the medical decision, it also helps maintain the sense of belonging to the medical community and the sharing of knowledge within it.

3. The organizational rules. When hospitals hire specialists, they internalize bodies of already codified knowledge and simultaneously codify other types of knowledge by institutionalizing models of behaviour and knowledge in norms and/or operational routines. Medical protocols, in particular, are based on the segmentation of therapy and surgery into one 'correct sequence' of microactions, and they result from a process of rationalization of medical knowledge (Berg, 1997). When performing the teleconsultancy, the cardiologists follow a protocol inscribed in the computer's software which requires them to complete all the fields on a form. Thus, the protocol structures the conversation between the two doctors.

4. Artefacts. Knowledge resides not only in humans and rules but also in artefacts such as the instruments, technologies and objects that participate in and constitute the setting of the activity. In the case considered here, the patient-file which the cardiologist must compile not only defines the sequence and the content of the questions put by the cardiologist to the general practitioner, it is also an instrument of organizational accountability. ${ }^{5}$ That is to say, the set of questions is not only predetermined by the form of interaction between the cardiologist and the general practitioner, it also mirrors the forms of knowledge deemed legitimate and relevant in that medical practice. Besides the patient-file, there is another artefact which shapes medical knowledge through the constraints and rules that it imposes. This is the software used in the service to regulate how the teleconsultancy report must be written. It makes accountable not so much the activity or interaction with the general practitioner as the rationality that reconstructs (a posteriori) the medical action in terms of legal liability. Moreover, use of a further artefact - the electrocardiograph (for recording the ECG) - incorporates the knowledge that has been 
necessary for its design and implementation. It is this technical object that transforms the impulses emitted by the human body into elements representing its activity. But, at the same time, the image of the patient furnished by the ECG artefact assumes value according to the narrative in which it is embedded - that is, as and when it is situated within a texture of interconnected practices.

5. The technological infrastructure. The teleconsultancy is made possible by a technological infrastructure consisting of computer, telephones, cables and electrocardiographs, but also of the languages and codes necessary to render them compatible, as well as a call centre responsible for interconnecting general practitioners, ECG traces, cardiologists and the transmission of reports. The practical knowledge mobilized by the teleconsultancy is therefore anchored in a technological infrastructure, that when it is in operation, is not visible/hearable in the telephone call, but on which the possibility of the teleconsultancy depends.

Knowledge, therefore, does not reside in the heads of people; on the contrary, it is anchored in the material world, and working requires activation of a fragmented system of knowledge (Bruni et al., 2007). The expression 'fragmented' is here preferred to 'distributed' to emphasize the fuzziness of the distribution and the negotiation between all those who interact within a specific working practice and possess different 'pieces' of knowledge which, as in a jigsaw puzzle, must be fitted together to acquire intelligibility.

I have used the example of the teleconsultancy in order to show that what we call 'knowledge' is a cooperative activity, an ongoing practical accomplishment. My purpose is also to underline that the way in which new technologies 'enter' medical practice is very close to what happens in many other computer-mediated types of work, where working at distance entails the dematerialization of work and the loss of sensitive knowledge. Observing, touching and listening to the patient is an activity typical of medical examinations which disappears in the teleconsultancy process, with the consequent loss of the sensory (aesthetic) abilities. Moreover, there is an impoverishment of the 'material-objective' basis of knowledge which is offset by an increase in communicative competence. Because the patient's body is absent, it is reintroduced and mainly represented by the ECG trace and the account given by the general practitioner. Compiling the clinical report becomes a cooperative activity mediated by information and communication technologies within a rarefied interactive space.

We may therefore start with the example of the teleconsultancy to propose an interpretative and methodological frame for analysis of 
situated practices as knowing-in-practice. Accordingly, the characteristics of practical knowledge are the following:

- A pragmatic stance. Practical knowledge is directed to doing, to taking decisions in situations, to solving problems, to maintaining and reproducing a community of practices.

- A specific temporality. Practical knowledge emerges from the situation and from situated action.

- An anchoring in materiality. Practical knowledge uses fragments of knowledge embedded in objects and technology, and in the material world that interacts with humans and interrogates them.

- An anchoring in discursive practices. Practical knowledge uses the discursive mobilization of cues for action and their positions within a narrative scheme that gives sense to what occurs phenomenologically.

- A historical and cultural anchoring. Practical knowledge is also mediated by what has happened in the past and has been learned from experience and in experience. If we consider the setting in which practices are developed, we must include within it both the institutional context and the social system of the division of labour and the rules that regulate social roles.

\subsection{TO SUM UP}

To briefly summarize the sociological study of practices, the sociologists who have made the greatest contribution to it - Garfinkel, Bourdieu and Giddens - are indebted to Schütz (1962) and his definition of the 'social world' as a reality constituted by innumerable and finite provinces of meaning. Following his phenomenological tradition, the world of everyday life is seen as province of meaning dominated and structured by the so-called 'natural attitude'. The world therefore is not the private world of the single individual, but an intersubjective world shared by all of us and in which we have, not a theoretical, but an eminently practical interest.

The vision of practical knowledge that derives from theories of practice and empirical research on organizational learning and knowing today merge into what have been called 'practice-based studies'. These studies are part of the critique of rationality and the use of rational models to interpret social action. In this sense, the purpose of studying work as practical knowledge and situated activity is to replace objective rationality (as a regime of 'optimizing' or 'satisficing' logic) with the logic of situation (and therefore a regime of 'contextual rationality'). On this view, the context in which work is undertaken is not pre-constituted. On the contrary, it is 
actively constructed in 'situational frames' which interpret situations by isolating them from the environment. Practising is thus 'knowing how' and knowing 'what next' in order to contribute to the ongoing situated working practice.

Studying work in its everyday settings requires that working practices and their day-by-day reproduction be assumed as the units of analysis. The attention therefore shifts from analysis of work as production to work as the reproduction of society and social relationships. The production of social life thus becomes a 'skilled performance' (Giddens, 1990, p.4), in that social practices are constructed (as ethnomethodology illustrates) as procedures, methods or techniques opportunely performed by social actors. Practice can thus be viewed in light of the idea of society put forward by Garfinkel (1967), that is, not as an already existing structure in which animals and humans can enter, but as a performance that must be constantly refined.

Whilst action is an individual act performed by a social actor and is considered in its unfolding, a practice is something more (although it is composed of activities and courses of action). What makes it recognizable and recognized is its being socially sustained and constantly reproduced. A practice is such if it is recognized by a community, and if it is sustained by a normative basis both ethical, affective and aesthetic. Communities of practitioners sustain their practices by negotiating and discussing what is a good practice, which of them is better or more beautiful, when a practice should be changed and how, or whether it should be discarded.

Large parts of our actions and interactions are not based on shared arrangements but instead on a set of tacit presuppositions, neither made explicit nor entirely explicable, and which are taken for granted. Knowing how to see (and therefore to develop a professional vision), knowing how to speak (to use technical vocabulary with competence) and knowing how to do: these, therefore, are the 'observable and reportable' competences that the researcher considers when describing and interpreting practices. As Llewellyn and Spence (2009) argue, in the first instance, practice is a members' phenomenon, something that members draw upon, monitor and orient to in real-time situated interactions.

The following assumptions ground the approach to practice as knowing-in-practice:

- Human activity in situations does not comply with absolute rationality, rather to a situated and contingent rationality. The reciprocal intelligibility of the actions of those involved in a practice derives from recognition of reciprocal intentions according to a plan considered a resource for action. 
- Cooperation in practice is the result of the constant adjustment of the unforeseen events which arise from the context.

- Technology is an artefact that transforms and distributes representations: it incorporates knowledge and ensures that, in the work environment, knowledge is distributed between human and nonhuman actors.

- Knowing-in-practice is a practical activity constructed by actors in situations and interactions which may occur face-to-face or be mediated by information and communication technologies, but which in all cases must be studied in situ.

In this chapter I draw mainly on an ethnomethodological understanding of practice, defining it processually, as an ongoing accomplishment. Thus, temporality and situatedness are at the forefront, together with the doing and talking that humans undertake in order to have a job done. I have referred to three classic studies in order to illustrate the single points of interest and application of practice-based studies and, in so doing, offer insights into their methodology:

- The pony express case illustrated how a practice is an ecology of interacting elements (such as the body and bodily knowledge; artefacts and the knowledge materialized in them; organizational and societal rules), and the context of a practice is not a simple container of it, but rather is a resource for practical reasoning and acting.

- The hospital ward case was an example of articulation work, and therefore of how arrangements of elements should be negotiated and renegotiated while practices unfold in time.

- The teleconsultancy case represented an instance of a practice that, in its being practised, connects all the 'pieces' of fragmented knowledge together into a coherent whole. It shows how knowingin-practice is achieved as a practical accomplishment.

\section{NOTES}

1. I do not discuss here the practice theory inspired by ethnomethodology. For a more in-depth look at this see Fox (2006); Llewellyn and Hindmarsh (2010); Nicolini (2012, chapter 6).

2. For an overview of research in practice-based studies see the 2000 special issue of the journal Organization, whose introduction presents practical knowledge as the third way between a mentalist conception of knowledge as a product of the mind and a conception of it as an object or new type of commodity (Gherardi, 2000). A reconstruction of the development of practice-based studies can be found in Corradi et al., (2010). The recent interest in organization studies gave rise to a number of literature reviews on 
practice-based theorizing about organizations: Erden et al., 2014; Jarzabkowski and Spee, 2009; Okhuysen and Bechky, 2009; Parmigiani and Howard-Grenville, 2011; Vaara and Whittington, 2012.

3. It is interesting also to consult a subsequent special issue, edited by Borzeix and Cochoy in 2008, which was a follow-up to the 1994 one, titled 'Work and activity theory: towards workplace studies?'. In that special issue there is an article by Licoppe (2008) that reconstructs the debate leading to the paradigm of situated action acknowledging the influence of four streams of thought: distributed cognition, activity theory, ethnomethodology as the foundation of workplace studies, and science and technology studies. He also explains the absence of the French-speaking community from the so-called 'practice turn' in terms of a preference for the word 'activity' instead of 'practice', since the latter term is too tied in France to the influence of Bourdieu's practice theory.

4. The term 'situated action' is used in the field of artificial intelligence and the study of man/machine interaction in opposition to the abstract representation of knowledge. Its best-known proponents, Winograd and Flores (1986) and Suchman (1987), argue that when designing interfaces, it is better to study the concrete use that people make of computers, rather than focusing on how people think or on what computers can do. Besides these authors, Lave (1988), who worked in the area of educational studies, contributed to the debate by showing that abstract knowledge (acquired in educational contexts, for example) is not transferable to the real world, and that there is a substantial difference between knowing in everyday situations and decontextualized knowing. Various disciplinary fields, therefore, have attacked the representational and cognitive conception of knowledge as produced in people's heads by mental processes.

5. The term 'accountability' is, in Garfinkel's words (1967, p.1): 'When I speak of accountable ... I mean observable-and-reportable, i.e. available to members as situated practices of looking-and-telling'. Literally, the term derives from the account used to explain what is happening to ourselves and to others. Accountability therefore comprises moral responsibility (of the person who explains) and reasonableness (of what is being explained). Also deriving from the same root is the word accounting, so that the adjective accountable means justifiable according to explicit and demonstrable procedures. 